\title{
Preparation of porous thin-film polymethylsiloxane microparticles in a W/O emulsion system
}

\author{
Shozi Mishima ${ }^{1}$, Tomohiko Okada ${ }^{1}$, Toshio Sakai ${ }^{1}$, Ryutaro Kiyono ${ }^{1}$ and Tetsuji Haeiwa ${ }^{2}$ \\ Porous thin-film polymethylsiloxane microparticles have been prepared successfully from octyltrichlorosilane and \\ methyltrichlorosilane in (water/oil) W/O emulsion systems by using several oil phases and changing the amount of the silanes or \\ of the surfactant Span 60. Hollow microspheres of various shell thicknesses $(120-180 \mathrm{~nm})$ and high surface area were prepared \\ by using four types of nonpolar solvents as the oil phase of the W/O emulsion system. The diameter of the spheres can also be \\ controlled $(1-1.6 \mu \mathrm{m})$ by using different oil phases. The results of thermal analysis, nitrogen adsorption isotherm, infrared \\ spectra and X-ray diffraction data showed that hollow microspheres of amorphous polymethylsiloxane with high surface area \\ $\left(360-385 \mathrm{~m}^{2} \mathrm{~g}^{-1}\right)$ can be obtained by heating the spheres in air at $673 \mathrm{~K}$; the polymethylsiloxane microspheres become \\ nonporous silica particles after calcination at $873 \mathrm{~K}$ for $3 \mathrm{~h}$. Cup-shape microparticles of polymethylsiloxane with nano-order \\ thickness $(20-120 \mathrm{~nm})$ were prepared by reducing the amount of silanes in the mixture. Small hollow particles were prepared by \\ replacing a portion of the octyltrichlorosilane with Span 60 .
}

Polymer Journal (2015) 47, 449-455; doi:10.1038/pj.2015.16; published online 25 March 2015

\section{INTRODUCTION}

Various attempts have been made to prepare silica hollow spheres ${ }^{1-11}$ because of their potential importance as new functional materials such as catalyst supports. Similar studies have also been reported for other metal oxides such as zeolite ${ }^{12-16}$ and titania. ${ }^{17-19}$ We Mishima et al. ${ }^{20}$ reported that hollow polymethylsiloxane microspheres prepared by using a (water/oil) W/O emulsion system can also be used as a new functional material that shows hydrophobicity, high surface area $\left(>300 \mathrm{~m}^{2} \mathrm{~g}^{-1}\right.$ ) and relatively high thermal stability (>673 K). By using the W/O emulsion system, various rattle-type core-shell particles were also fabricated by introducing 12-tungstophosphoric acid, ${ }^{21}$ its cesium salts, ${ }^{22}$ cobalt oxides, ${ }^{23}$ metallic cobalt ${ }^{24}$ and iron compounds ${ }^{25}$ as the core substance into hollow polymethylsiloxane microspheres.

In recent years, catalyst thin films ${ }^{26}$ prepared by supporting metals or metal oxides on various thin films have been receiving widespread attention because of their promising application as highly active and highly selective catalysts. For example, Au on titania of less than $100 \mathrm{~nm}$ thickness, ${ }^{27} \mathrm{Pt}$ on mesoporous titania thin films, ${ }^{28}$ amorphous iridium oxide films on conducting glass substrate ${ }^{29}$ and $\mathrm{Au}$ on $\mathrm{SiO}_{x}{ }^{30}$ thin films have been prepared and applied as catalysts. In general, catalyst thin films should be formed on physically stable supporting substrates, such as glass plates and ceramic wafers to protect the weak thin film from physical shock. If physically stable thin film catalysts could be fabricated without supporting substrates, they would become promising catalysts or catalyst supports with high efficiency due to their high surface area and the reduction in heat and mass transport limitations during catalytic reactions. A strategy to obtain physically stable catalyst thin films is the preparation of catalysts in the form of thin-film microparticles (for example, $1-3 \mu \mathrm{m}$ in diameter and 10 $100 \mathrm{~nm}$ in thickness). The small diameter and the low aspect ratio of the thin-film microparticles make the particles more stable to physical shock than large particles (for example, $>10 \mu \mathrm{m}$ in diameter).

Hollow microspheres with thin-film shells can also be regarded as a type of thin-film particle. Several studies ${ }^{5,6,11}$ have addressed the fabrication of hollow thin-film silica microparticles. Zoldesi et al., ${ }^{5,6}$ for example, made hollow microspheres, cup-shaped microcapsules and microballoons of silica from tetraethoxysilane in emulsion systems. Hollow thin-film microparticles are interesting as new catalysts and catalyst supports. In the present study, preparation of porous thin-film microparticles of polymethylsiloxane instead of metal oxides was attempted as a means of obtaining new types of porous thin-film microparticles.

\section{EXPERIMENTAL PROCEDURE}

Materials

Octyltrichlorosilane (OTCS) and methyltrichlorosilane (MTCS) were purchased from Aldrich Chemical (St Louis, MO, USA) and Shin-Etsu Chemical (Tokyo, Japan), respectively. Toluene, isooctane (2,2,4-trimethylpentane), trichloroethylene and $n$-hexane (GR grade) were purchased from Wako Chemical (Osaka, Japan). Sorbitan monostearate (Span 60; see the formula shown in Supplementary Figure S1) was obtained from Wako Chemical. All of the materials were used as received.

\footnotetext{
${ }^{1}$ Department of Chemistry and Material Engineering, Faculty of Engineering, Shinshu University, Nagano, Japan and ${ }^{2}$ Department of Information Technology, Faculty of Engineering, Shinshu University, Nagano, Japan

Correspondence: Professor S Mishima, Department of Chemistry and Material Engineering, Faculty of Engineering, Shinshu University, Wakasato 4-17-1, Nagano 380-8553, Japan.

E-mail: smisima@shinshu-u.ac.jp

Received 14 July 2014; revised 31 January 2015; accepted 5 February 2015; published online 25 March 2015
} 


\section{Sample preparation}

The following method is the representative procedure (referred to hereinafter as the standard method) for preparing microparticles: first, a W/O emulsion was prepared by mixing $0.75 \mathrm{ml}$ of water and $2.97 \mathrm{~g}(12 \mathrm{mmol})$ of OTCS dissolved in $50 \mathrm{ml}$ of a solvent (toluene, trichloroethylene, $n$-heptane or isooctane) as the oil phase followed by ultrasonic agitation $(45 \mathrm{kHz})$ for $5 \mathrm{~min}$; then, $1.35 \mathrm{~g}$ $(9.0 \mathrm{mmol})$ of MTCS dissolved in $10 \mathrm{ml}$ of the same solvent was poured into the W/O emulsion under magnetic stirring, and the mixture was stirred at room temperature for more than $3 \mathrm{~h}$ for the completion of the reaction. During the reaction, water-saturated air was continuously supplied $\left(0.11 \mathrm{~min}^{-1}\right)$ to remove evolved hydrogen chloride and to accelerate the hydrolysis and polymerization of OTCS and MTCS. The obtained solid was separated by centrifugation, washed thoroughly with the same solvent and dried at $323 \mathrm{~K}$ for $24 \mathrm{~h}$, then washed with ethanol aqueous solution (50\% in volume) and dried at $393 \mathrm{~K}$ for more than $3 \mathrm{~h}$. Finally, the obtained solid samples were calcined at 673 or $873 \mathrm{~K}$ in an electronic furnace.

To prepare thin-film particles, the amounts of OTCS and MTCS added to the W/O emulsion system were reduced to 50, 20 and $10 \%$, simultaneously, of the amounts used for the standard method by using isooctane as the oil phase.

To examine the effect of the emulsifier on the shape of the product, a portion of the OTCS used in the standard method was replaced with Span 60 such that the sum of the amounts of OTCS and Span 60 was kept constant $(12 \mathrm{mmol})$.

\section{Characterization}

Thermogravimetric-differential thermal analyses were carried out by using a Shimadzu DTG-50 (Shimadzu, Kyoto, Japan) at a heating rate of $10 \mathrm{~K} \mathrm{~min}^{-1}$. Fourier transform infrared spectra were recorded on a Shimadzu FT-IR 4200A (Shimadzu) by applying the $\mathrm{KBr}$ pelletizing method. Scanning electron micrographs were obtained on a Hitachi S-4200 (Hitachi, Tokyo, Japan) field-emission scanning electron microscope (SEM). X-ray diffraction patterns were obtained using a Rigaku RINT 2200V/PC (monochromatic $\mathrm{Cu} \mathrm{K}_{\alpha}$, Rigaku, Tokyo, Japan) operated at $20 \mathrm{~mA}, 40 \mathrm{kV}$. Nitrogen adsorptiondesorption isotherms at $77 \mathrm{~K}$ were obtained by using a Micromeritics ASAP2000 (Micromeritics, Norcross, GA, USA). Solid-state ${ }^{13} \mathrm{C}$ magic angle spinning NMR spectra were recorded on a Bruker ASCEND 500 spectrometer (Bruker, Billerica, MA, USA) at a resonance frequency of $125.77 \mathrm{MHz}$ and a spinning frequency of $10 \mathrm{kHz}$.

\section{RESULTS AND DISCUSSION}

Effect of the type of oil phase on the shape of products

SEM images of particles prepared using the standard method with toluene as the oil phase are shown in Figure 1. As shown in Figure 1a, prepared particles calcined at $673 \mathrm{~K}$ for $3 \mathrm{~h}$ are microspheres of $1-5 \mu \mathrm{m}$ in diameter; as shown in Figure $1 \mathrm{~b}$, the appearance of these microspheres after cleavage in a mortar suggests that the particles are hollow with a large void core and a relatively thick shell $(\sim 180 \mathrm{~nm})$. Similar hollow spheres were obtained by using isooctane, trichloroethylene and $n$-heptane as the oil phase. These results demonstrate that hollow microspheres can be prepared from OTCS and MTCS in W/O emulsion systems using nonpolar solvents as the oil phase.

A provable mechanism for the formation of hollow microspheres was proposed in our previous paper. ${ }^{20}$ Namely, in the W/O emulsion produced by ultrasonic agitation, OTCS aggregates at the water-oil interface and stabilizes water microdroplets, operating as an emulsifier because of the hydrophobic octyl group and the hydrophilic $\mathrm{Si}-\mathrm{Cl}_{3}$ group of OTCS. Because MTCS, with its hydrophobic methyl group, may also be apt to aggregate at the water-oil interface, hydrolysis and polymerization of MTCS and OTCS would proceed at the water-oil interface. As a result, hollow microspheres are formed by using water microdroplets as the template.

The yield, surface area, particle size and shell thickness of the samples prepared by using four types of solvent as the oil phase are summarized in Table 1 together with the dielectric constants, $\varepsilon_{r}$, of the solvents. The same yields $(28 \%)$ were obtained independent of the
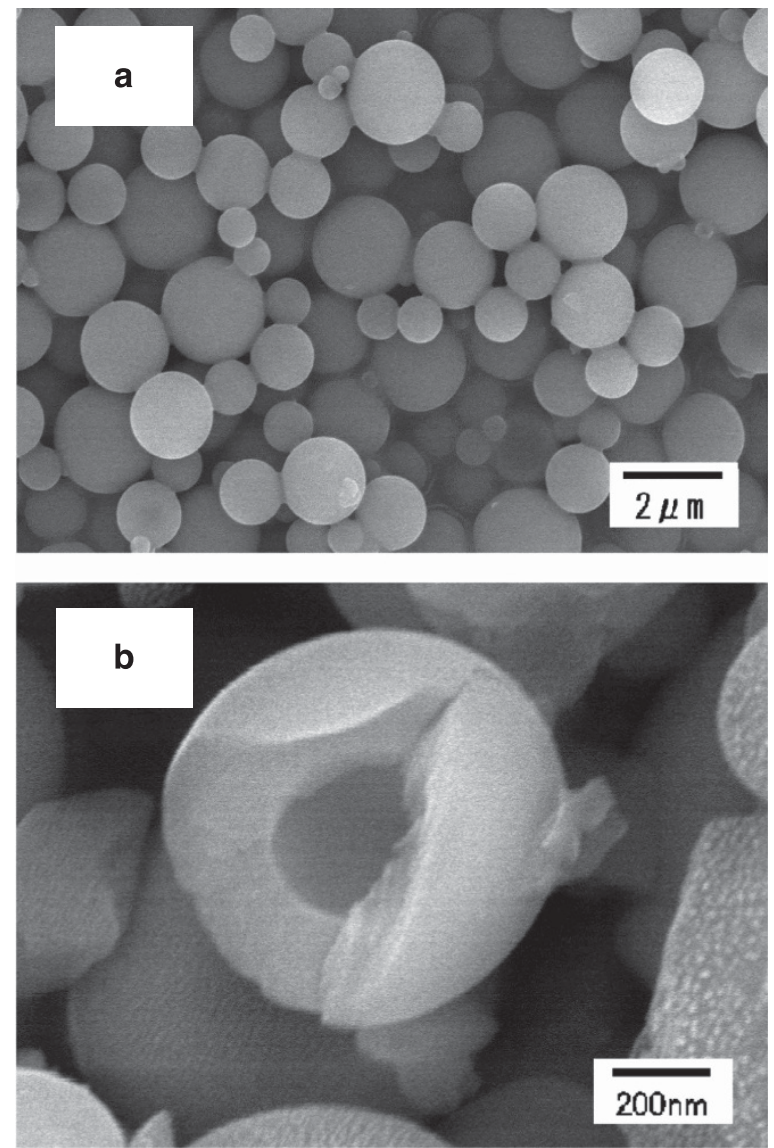

Figure 1 Scanning electron microscopic images of (a) microspheres obtained using toluene as the oil phase and calcined at $673 \mathrm{~K}$ for $3 \mathrm{~h}$ in air and (b) a cleaved microsphere.

Table 1 Yields and physical properties of hollow particles obtained by using four kinds of solvent as oil phase and calcined at $673 \mathrm{~K}$ for $3 \mathrm{~h}$

\begin{tabular}{|c|c|c|c|c|}
\hline Solvent as oil phase ${ }^{a}$ & Yield $\mathrm{b} / \%$ & $\begin{array}{l}\text { BET surface } \\
\text { area } / \mathrm{m}^{2} \mathrm{~g}^{-1}\end{array}$ & $\begin{array}{c}\text { Particle } \\
\text { diameter } / \mu m\end{array}$ & $\begin{array}{c}\text { Shell } \\
\text { thickness } / n m\end{array}$ \\
\hline Toluene $\left(\varepsilon_{r}=2.4\right)$ & 28 & 384 & 1.6 & 180 \\
\hline Trichloroethylene $(\varepsilon=3.3)$ & 28 & 385 & 1.5 & 160 \\
\hline$n$-Heptane $\left(\varepsilon_{r}=1.9\right)$ & 28 & 360 & 1.0 & 120 \\
\hline Isooctane $\left(\varepsilon_{r}=1.9\right)$ & 28 & 382 & 1.0 & 120 \\
\hline
\end{tabular}

Abbreviations: MTCS, methyltrichlorosilane; OTCS, octyltrichlorosilane.

avalues in parentheses are the dielectric constant $\varepsilon_{r}$ at $293 \mathrm{~K}$.

${ }^{b}$ Calculated regarding all of OTCS and MTCS become solid polymer.

cAverage of 400 particles.

${ }^{d}$ Average of 10 particles after heat treatment at $673 \mathrm{~K}$ for $3 \mathrm{~h}$ in the air.

type of oil phase. The low yield suggests that a portion of the OTCS and MTCS added to the system remains in the oil phase as a monomer or an oligomer even after completion of the reaction. The specific surface areas shown in the table suggest that the shells of all hollow particles after calcination at $673 \mathrm{~K}$ for $3 \mathrm{~h}$ are porous (360-385 $\mathrm{m}^{2} \mathrm{~g}^{-1}$ ), independent of the type of oil phase used.

As shown in Table 1, particles obtained by using toluene and trichloroethylene have similar average particle diameters $(1.5-1.6 \mu \mathrm{m})$ and shell thicknesses $(160-180 \mathrm{~nm})$. On the other hand, particles obtained by using $n$-heptane and iso-octane are small $(1.0 \mu \mathrm{m})$ with thin shells $(120 \mathrm{~nm})$ compared with those obtained by using toluene 
and trichloroethylene. Because the sizes of hollow particles depend on the size of the water droplets that act as templates in the emulsion, it is suggested that solvents of low dielectric constant $\left(\varepsilon_{r}=1.9\right)$, such as $n$ heptane and isooctane, stabilizes smaller water droplets than solvents of high dielectric constant, such as toluene $\left(\varepsilon_{r}=2.4\right)$ and trichloroethylene $\left(\varepsilon_{r}=3.3\right)$. From the results described above, it is concluded that the average size and shell thickness of the particles can be controlled in the range $1.0-1.6 \mu \mathrm{m}$ and $120-180 \mathrm{~nm}$, respectively, by using solvents with different dielectric constants as the oil phase.

\section{Thermal analysis}

The results of thermal analyses of samples obtained by using toluene as the oil phase are shown in Figure 2. Two exothermic peaks accompanying weight loss are observed at $\sim 500-600 \mathrm{~K}$ and $800 \mathrm{~K}$. Considering that the particles obtained here can be regarded as copolymers of polyoctylsiloxane and polymethylsiloxane, the exothermic peak at 500-600 K accompanying weight loss can be attributed to oxidation of the octyl group, which is thermally unstable compared with the methyl group. Similarly, the peak at $\sim 800 \mathrm{~K}$ observed with weight loss can be ascribed to oxidation of the methyl group. These results suggest that the prepared particles are copolymers of polyoctylsiloxane and polymethylsiloxane. After heat treatment at $500-600 \mathrm{~K}$, the copolymer particles become polymethylsiloxane, whereas after treatment at $\sim 800 \mathrm{~K}$ they become polysiloxane (silica). Similar results were obtained for particles obtained by using other oil phases; it is therefore suggested that the particles obtained by using other oil phases are also copolymers of polyoctylsiloxane and polymethylsiloxane.

In Figure 2, the weight loss observed at $\sim 500-600 \mathrm{~K}$ was $\sim 19$ $31 \mathrm{wt} \%$, which can be ascribed to the oxidation of $\mathrm{C}_{8} \mathrm{H}_{17}-\mathrm{SiO}_{1.5}$ to $\mathrm{SiO}_{2}$. On the other hand, the weight loss observed at $\sim 800 \mathrm{~K}$ was $\sim 5.7-8.9 \mathrm{wt} \%$; this loss can be ascribed to the oxidation of $\mathrm{CH}_{3}-\mathrm{SiO}_{1.5}$ to $\mathrm{SiO}_{2}$. Based on the weight loss analysis, it was concluded that the molar ratio $\mathrm{CH}_{3}-\mathrm{SiO}_{1.5}: \mathrm{C}_{8} \mathrm{H}_{17}-\mathrm{SiO}_{1.5}: \mathrm{SiO}_{2}$ is equal to 1:0.2-0.4:0 for the as-made sample, 1:0:0.2-0.4 for the sample heat treated at $\sim 500-$ $600 \mathrm{~K}$, and 0: 0: 1 for the sample heat treated at $\sim 800 \mathrm{~K}$. It is noted that the small weight loss at $\sim 800 \mathrm{~K}$ is because of the small difference in molecular weight of $\mathrm{CH}_{3}-\mathrm{SiO}_{1.5}\left(67.1 \mathrm{~g} \mathrm{~mol}^{-1}\right)$ and that of $\mathrm{SiO}_{2}$ $\left(60.1 \mathrm{~g} \mathrm{~mol}^{-1}\right)$. It can be concluded from the results that the particles heat treated at $\sim 500-600 \mathrm{~K}$ contain large amounts of $\mathrm{CH}_{3}-\mathrm{SiO}_{1.5}$ $(>70 \mathrm{~mol} \%)$ in addition to a small amount of $\mathrm{SiO}_{2}(16-29 \mathrm{~mol} \%)$; therefore, these particles can be regarded as polymethylsiloxanes.

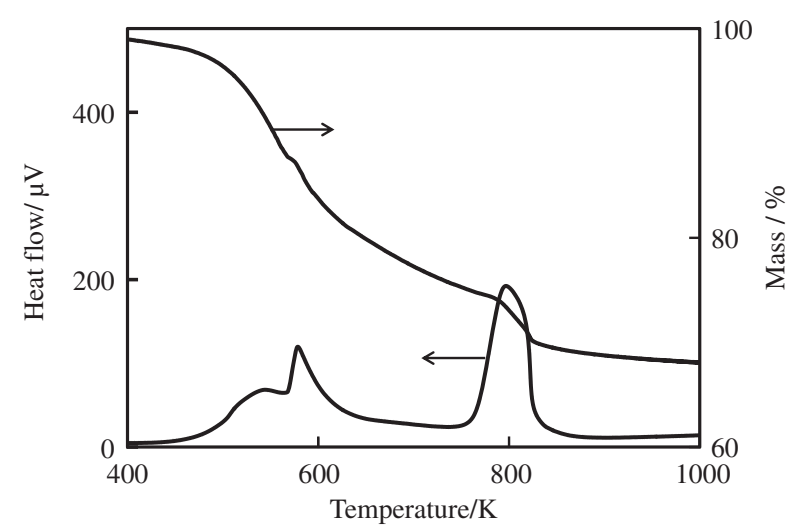

Figure 2 The results of thermal analysis of hollow microspheres prepared from octyltrichlorosilane and methyltrichlorosilane in a water/oil emulsion system by using toluene as the oil phase.

\section{IR spectra}

The Fourier transform infrared spectra of hollow microspheres prepared by using toluene as the oil phase are shown in Figure 3. Curve (a) shows the IR spectrum of an as-made sample dried at $393 \mathrm{~K}$. Because the results of the thermal analysis described above showed that this sample can be regarded as a copolymer of polyoctylsiloxane and polymethylsiloxane, the observed bands at $\sim 2900 \mathrm{~cm}^{-1}$ can be assigned to $\mathrm{C}-\mathrm{H}$ stretching vibrations of the octyl and methyl groups. Similarly, the bands at $\sim 1500-1800 \mathrm{~cm}^{-1}$ can be assigned to C-H deformation vibrations of the octyl and methyl groups. Spectrum (b) of the sample heat treated at $673 \mathrm{~K}$ also gives $\mathrm{C}-\mathrm{H}$ stretching and deformation bands. From the results of the thermal analysis described above, this sample can be regarded as polymethylsiloxane, and the observed stretching and deformation bands can be assigned to the methyl group. Curve (c) shows the spectrum of a sample that was calcined at $873 \mathrm{~K}$ for $3 \mathrm{~h}$. The results of the thermal analysis suggest that this sample can be regarded as silica. Actually, this sample shows no absorption bands corresponding to octyl or methyl groups, and the spectrum qualitatively agrees with that of silica gel. From the infrared spectra described above, it is concluded that hollow spheres dried at $393 \mathrm{~K}$ and those calcined at 673 and $873 \mathrm{~K}$ for $3 \mathrm{~h}$ are a copolymer, polymethylsiloxane and silica, respectively, consistent with the results of thermal analyses. Similar infrared spectra were obtained for the particles prepared by using other oil phases.

\section{XRD analysis}

X-ray diffraction patterns of particles obtained by using toluene as the oil phase are shown in Figure 4. Curves (a), (b) and (c) show the patterns obtained from samples dried at $393 \mathrm{~K}$ and calcined at 673 and $873 \mathrm{~K}$ for $3 \mathrm{~h}$, respectively. Because none of the samples yield a sharp diffraction peak, they can all be regarded as amorphous independent of treating temperature. Considering the results of the IR spectra described above, the broad diffraction peak at approximately $2 \theta=20$ $25^{\circ}$ observed in curves (a)-(c) is ascribed to amorphous silica, while the broad peak at $\sim 2 \theta=10^{\circ}$ observed in curves (a) and (b) may be ascribed to polymethylsiloxane, and the broad peak at $\sim 2 \theta=5^{\circ}$ observed in curve (a) may be ascribed to polyoctylsiloxane. However, the detailed structures corresponding to the diffraction peaks at $2 \theta=5^{\circ}$ and $10^{\circ}$ are not clear at present. Similar diffraction patterns were obtained for samples prepared by using other oil phases.

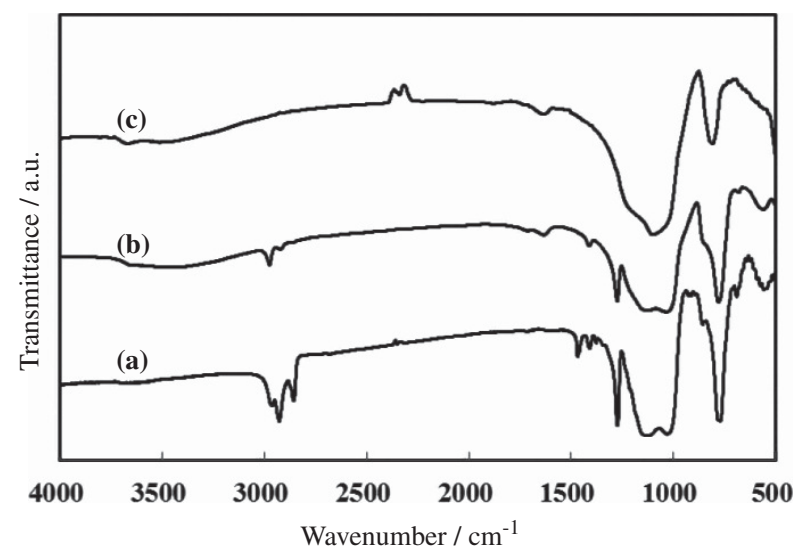

Figure 3 Fourier transform infrared spectra of hollow microspheres prepared from octyltrichlorosilane and methyltrichlorosilane by using toluene as the oil phase. The samples were (a) dried at $393 \mathrm{~K}$, (b) heat-treated at $673 \mathrm{~K}$ or (c) $873 \mathrm{~K}$ for $3 \mathrm{~h}$ in air. 
Effects of the amounts of OTCS and MTCS used to prepare particles To examine the effects of the amount of OTCS and MTCS in the mixture on the shape of the resulting particles, samples were prepared by using isooctane as the oil phase with varying amounts of OTCS and MTCS. Samples prepared by using 50, 20 and 10\% of OTCS and MTCS compared with those of the standard method are denoted as S-1, S-2 and S-3, respectively, and samples obtained by the standard

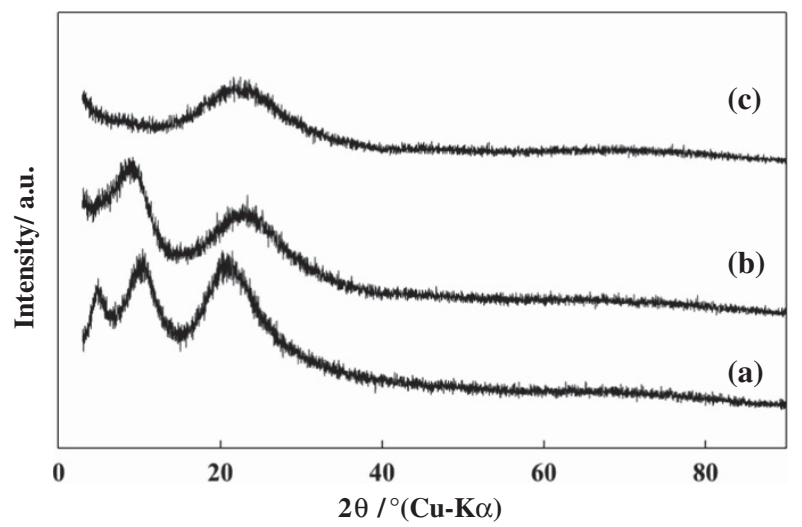

Figure $4 \mathrm{X}$-ray diffraction patterns of hollow spheres prepared using toluene as the oil phase. The samples were (a) dried at $393 \mathrm{~K}$, (b) heat treated at $673 \mathrm{~K}$ or (c) $873 \mathrm{~K}$ for $3 \mathrm{~h}$ in air. method are denoted as S-0 hereinafter. SEM images of the particles after calcination at $673 \mathrm{~K}$ for $3 \mathrm{~h}$ are shown in Figure 5. Although particles prepared by the standard method (S-0) are spherical, the majority of the S-1, S-2 and S-3 particles are cup shape and they become thin and large when the amount of MTCS and OTCS used in the preparation is reduced. These SEM images suggest that the shells of the hollow spheres become thin when MTCS and OTCS are reduced, accompanying their deformation from hollow spheres to cup-shape particles.

The yields and physical characteristics of S-0, S-1, S-2 and S-3 particles are summarized in Table 2. The yield of particles decreases when the amounts of OTCS and MTCS are reduced. The low yields suggest that a portion of the OTCS and MTCS added to the W/O emulsion exists as monomers or oligomers in the oil phase, as described for the low yields shown in Table 1, and that the yield is further reduced when the amount of OTCS and MTCS is reduced.

The size of S- 0 particles is $0.5-1 \mu \mathrm{m}$, as shown in Table 2 . The size of the particles increases in the order S-1 $(1-1.5 \mu \mathrm{m}), \mathrm{S}-2(3-4 \mu \mathrm{m})$ and S-3 $(>4 \mu \mathrm{m})$. These results suggest that the particles become larger when the amounts of OTCS and MTCS added to the system are reduced. As indicated in the table, S-0 is a sphere, and the average shell thickness is $\sim 120 \mathrm{~nm}$. On the other hand, S-1, S-2 and S-3 are cup shape, and the average shell thickness decreases in the order S-1 $(\sim$ $90 \mathrm{~nm}), \mathrm{S}-2(\sim 40 \mathrm{~nm})$ and S-3 $(\sim 20 \mathrm{~nm})$. It is noteworthy that the shell thickness of S-3 is only $\sim 20 \mathrm{~nm}$. These results suggest that the
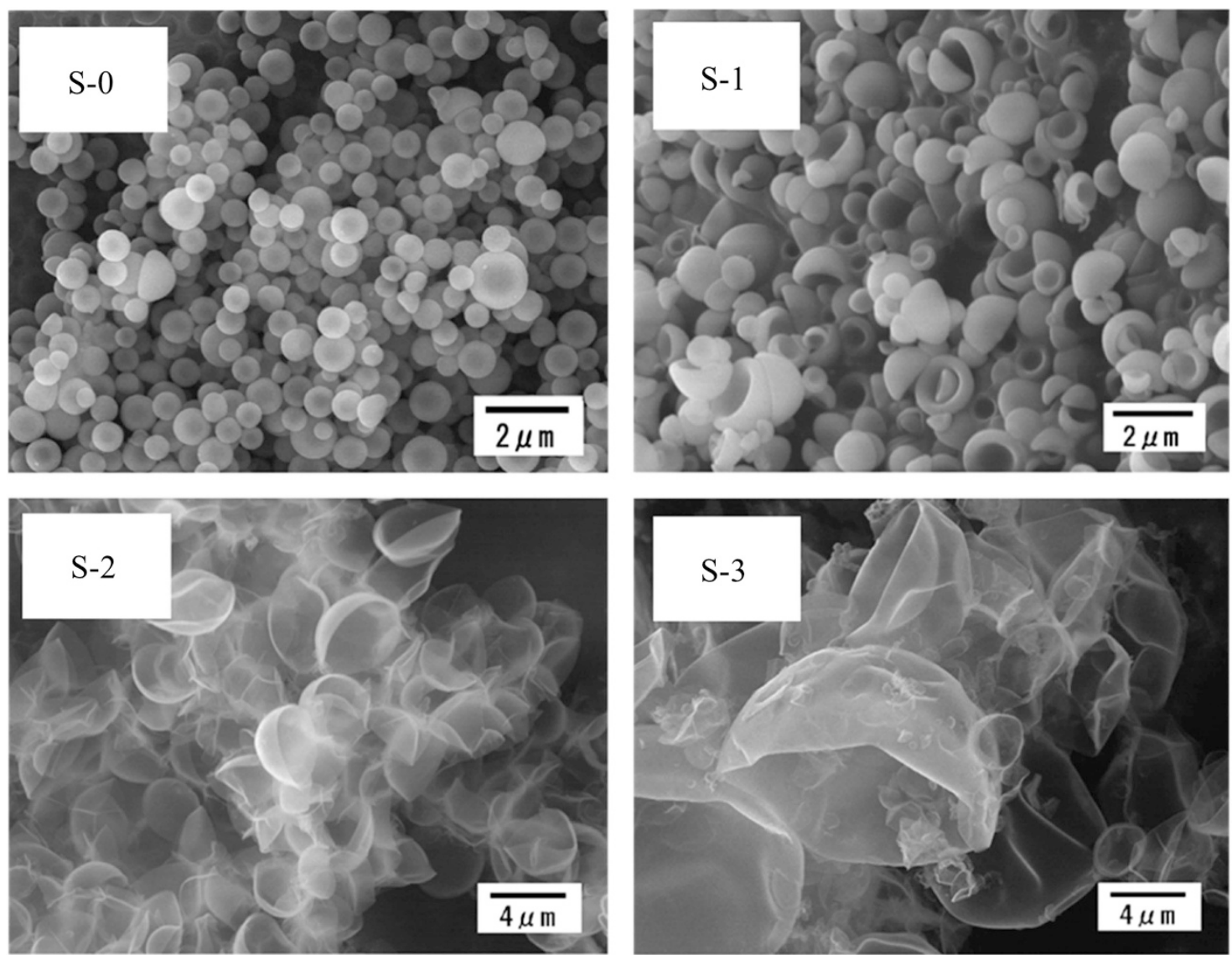

Figure 5 Effect of the amount of octyltrichlorosilane and methyltrichlorosilane on the shape of the prepared particles. Sample S-0 consists of particles obtained by the standard method. Samples S-1, S-2 and S-3 consist of particles obtained using 50, 20 and $10 \%$ of the octyltrichlorosilane and methyltrichlorosilane, respectively, used in the standard method. 
Table 2 Results of particle preparation by using different amounts of MTCS and OTCS by using isooctane as the oil phase

\begin{tabular}{|c|c|c|c|c|c|c|c|}
\hline Sample & OTCS $/ \mathrm{mol}$ & MTCS/mol & Yield $/ \%$ & BET surface areab $/ m^{2} g^{-1}$ & Particle size $\mathrm{c} / \mu \mathrm{m}$ & Shape & Shell thickness $/ / n m$ \\
\hline S-O & 12 & 9 & 28 & 382 & $0.5-1$ & Sphere & 120 \\
\hline S-1 & 6 & 4.5 & 25 & 372 & $1-1.5$ & Bowl & 90 \\
\hline S-3 & 1.2 & 0.9 & 14 & 329 & $>4$ & Bowl and film & 20 \\
\hline
\end{tabular}

Abbreviations: MTCS, methyltrichlorosilane; OTCS, octyltrichlorosilane.

aEstimated regarding all of OTCS and MTCS become solid by hydrolysis and polycondensation.

bMeasured after heat treatment at $673 \mathrm{~K}$ for $3 \mathrm{~h}$ in air.

${ }^{\mathrm{C}}$ Roughly estimated size of major parts of particles.

${ }^{d}$ Roughly estimated average value of 10 particles.

shell thickness of the particles can be easily and widely (20-200 nm) controlled by using different amounts of OTCS and MTCS in the preparation mixture. The cup-shape microparticles with nano-walls obtained here are interesting because they represent a new material with a large outer surface area.

It is likely that the size and number of water microdroplets in the emulsion depend on the amount of OTCS added to the emulsion and that these microdroplets are the dominant factor that determines the size and shell thickness of the prepared particles. Another strong possibility is that the size and number of water droplets remain constant independent of the amount of OTCS. In this case, the size and shell thickness of the particles would depend on the amount of MTCS added to the emulsion. In addition, in both cases described above, consumption of water during hydrolysis and resulting dehydration of the silanes would result in shrinkage of the water microdroplets. Further experimental study is needed to elucidate the dominant factors that determine the size and the shell thickness of the particles.

As shown in Table 2, all the samples have large specific surface areas (315-382 $\mathrm{m}^{2} \mathrm{~g}^{-1}$ ) that are independent of the thickness of the shell. These results show that the shells of the particles are porous.

Solid-state ${ }^{13} \mathrm{C}$ magic angle spinning NMR spectra of S-2 are shown in Figure 6. Spectra (a), (b) and (c) correspond to S-2 dried at $393 \mathrm{~K}$, heat treated at $673 \mathrm{~K}$ and at $873 \mathrm{~K}$ for $3 \mathrm{~h}$ in air, respectively. By comparing these results with those reported in the literature, ${ }^{31}$ peaks $1-8$ of spectrum (a) can be attributed to the bonding of an octyl group to a silicon atom. The peak at $\sim 0$ p.p.m. can be assigned to methyl group bonding to a silicon atom. Thus, dried S-2 can be considered a copolymer of polyoctylsiloxane and polymethylsiloxane. For spectrum (b), peaks that could be attributed to an octyl group have disappeared and only the peak of a methyl group can be observed at $\sim 0$ p.p.m. These results suggest that S-2 calcined at $673 \mathrm{~K}$ can be regarded as polymethylsiloxane. For spectrum (c), peaks that could be assigned to octyl and methyl groups are no longer observed, suggesting that S- 2 calcined at $873 \mathrm{~K}$ can be regarded as silica. Because the results obtained here agree qualitatively with those obtained from the thermal data shown in Figure 2 and the IR spectra shown in Figure 3, it is concluded that the polymethylsiloxane particles with very-thin films $(\sim 40 \mathrm{~nm})$ obtained here as S-2 show the same thermal stability as samples prepared by the standard method.

Effect of surfactant on the shape of the prepared particles

To examine the effect of surfactant on the shape of the prepared particles, a portion of the OTCS used in the standard method (12 mol) was replaced with the same molar amount of the surfactant Span 60. Toluene, a good solvent for Span 60, was used as the oil phase. SEM images of the obtained products are shown in Figure 7. The samples

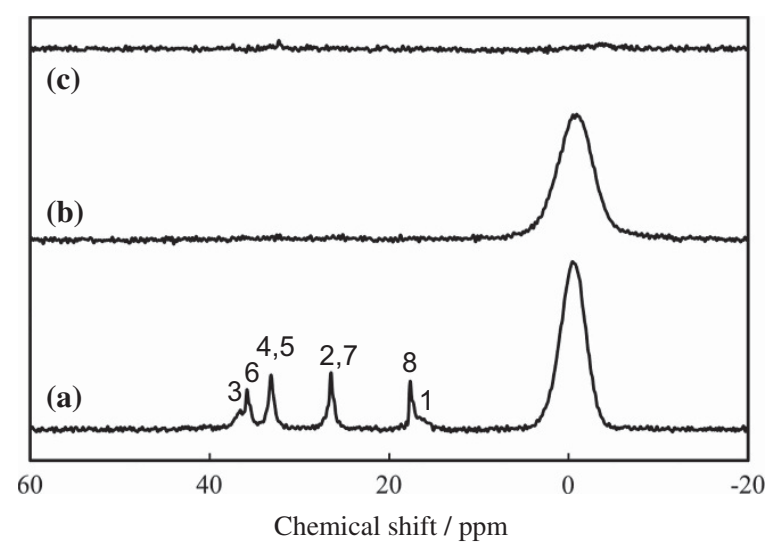

Figure 6 Solid-state ${ }^{13} \mathrm{C}$ magic angle spinning nuclear magnetic resonance spectra of S-2 particles (a) as made, (b) after heat treatment at $673 \mathrm{~K}$ or (c) at $873 \mathrm{~K}$ for $3 \mathrm{~h}$ in air.

prepared by replacing 1 and 5\% of the OTCS with Span 60 (denoted S-4 and S-5, respectively) are small spherical hollow particles. The samples prepared by replacing 10, and 50\% of the OTCS with Span 60 (denoted S-6 and S-7, respectively) are deformed or unshaped products. It is obvious that the obtained particles become small when the amount of Span 60 used to replace OTCS is increased. Because the size of the obtained particles should depend on the size of the water microdroplets in the $\mathrm{W} / \mathrm{O}$ emulsion, it is suggested that the presence of large amounts of Span 60 in the emulsion reduces the size of the water droplets.

The results and the morphology of the particles are summarized in Table 3. The data in the table show that the yields of products become small when the amount of Span 60 is increased. In particular, the yields are very small $(0.1-1 \%)$ for samples prepared by replacing $50 \%$ (S-7) or $100 \%$ (S-8) of the OTCS with Span 60. These results suggest that the presence of a large amount of Span 60 prevents the polymerization of OTCS and MTCS. It can be observed from the particle distribution in the table that the obtained particles become small when the amount of Span 60 is increased; specifically, the particle sizes are $0.5-6,0.5-4,0.1-2$ and $0.5-1 \mu \mathrm{m}$ for S- 0, S- 4, S- 5 and S-6, respectively. As shown in Table 3, the specific surface areas of samples S-4, S-5 and S- 6 calcined at $673 \mathrm{~K}$ for $3 \mathrm{~h}$ are relatively large $\left(331-576 \mathrm{~m}^{2} \mathrm{~g}^{-1}\right)$, so that particles obtained in the presence of Span 60 can also be regarded as porous material.

The data show that the size of the hollow particles can be tightly controlled by replacing a portion of the OTCS with Span 60 and that the shells of the obtained particles are porous. 

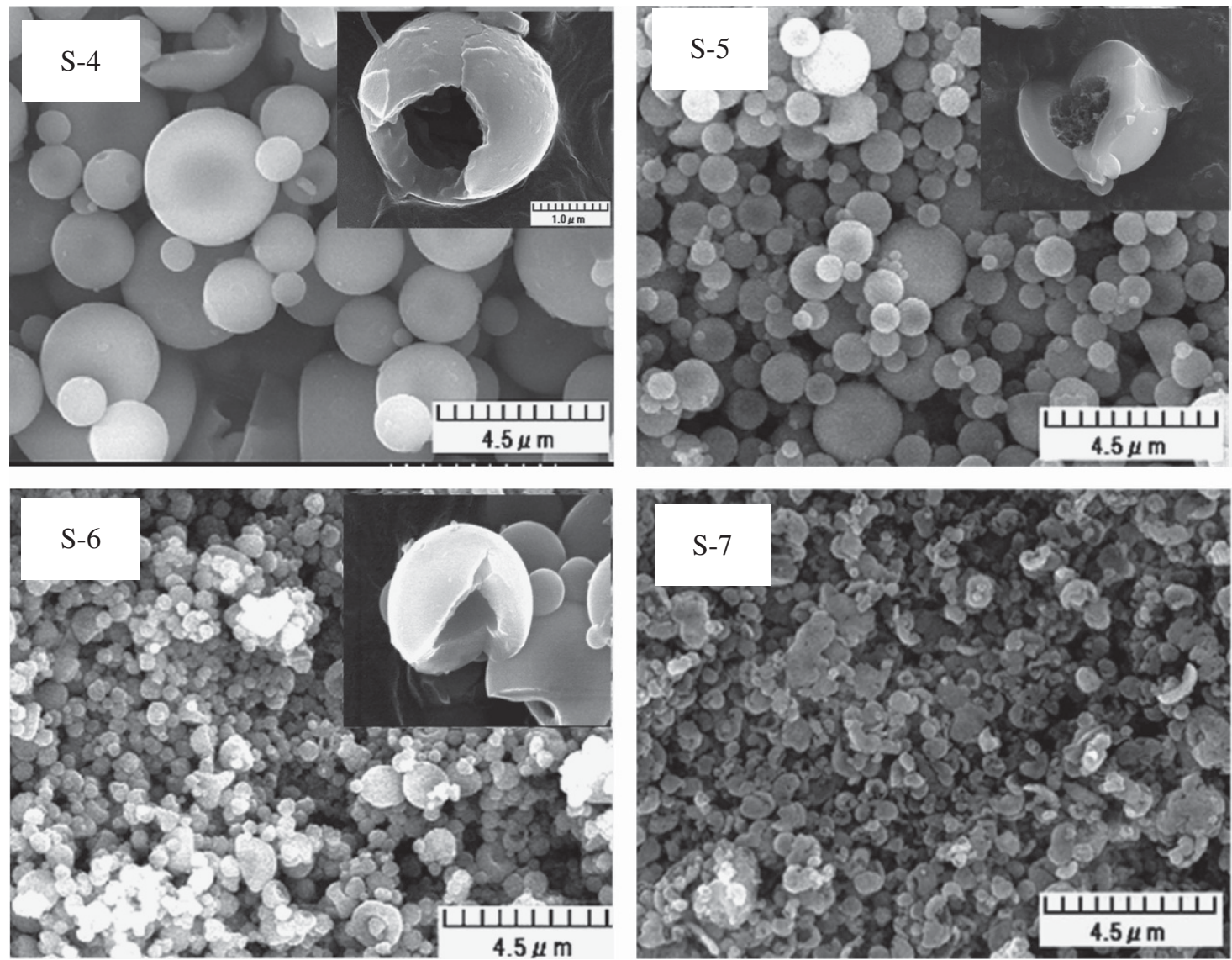

Figure 7 Scanning electron microscopic images of particles obtained by adding different amounts of Span 60 to isooctane as the oil phase. For samples S-4, S-5, S-6 and S-7, OTCS was replaced with 1.0, 5.0, 10.0 and 50\% Span 60, respectively. The insets of photographs of S-4, S-5 and S-6 show scanning electron microscopic images of a particle cleaved in a mortar.

Table 3 Results of particle preparation in the presence of Span 60 by using toluene as the oil phase

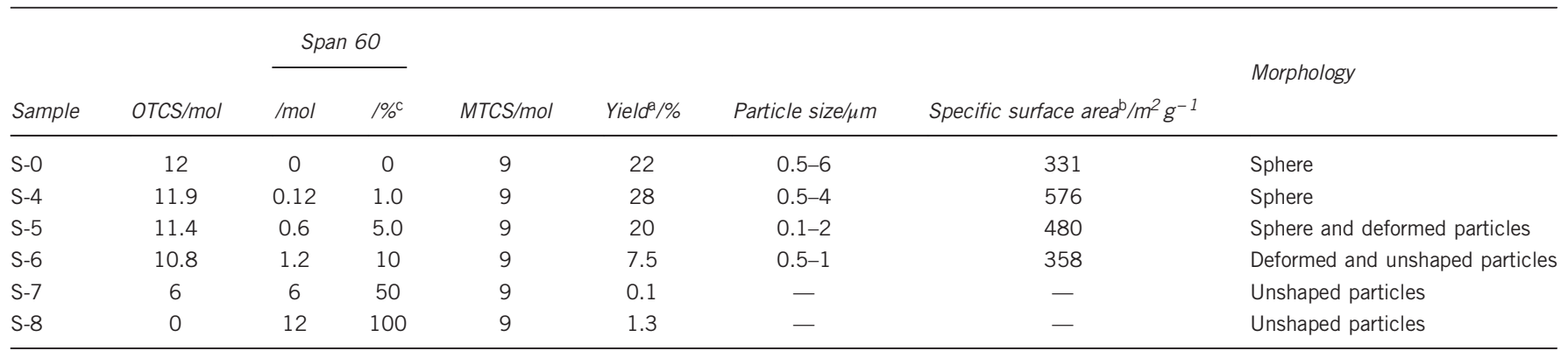

Abbreviations: MTCS, methyltrichlorosilane; OTCS, octyltrichlorosilane.

aEstimated regarding all of OTCS and MTCS become solid of polysiloxane.

bMeasured for samples after heat treatment at $673 \mathrm{~K}$ for $3 \mathrm{~h}$ in air.

CCalculated by the equation: the amount (mol) of Span $60 \times 100 /$ sum of the amount (mol) of OTCS and Span 60 .

\section{CONCLUSION}

As described above, it has been demonstrated that porous thin-film polymethylsiloxane microparticles can be prepared using W/O emulsion systems. These particles are porous $\left(360-385 \mathrm{~m}^{2} \mathrm{~g}^{-1}\right)$ and stable up to $673 \mathrm{~K}$. The mean diameter of the microparticles can be controlled within the range $1-1.6 \mu \mathrm{m}$ by using nonpolar solvents with different dielectric constants. The thickness of the polymethylsiloxane microparticles can be controlled easily over a broad range $(2-200 \mathrm{~nm})$ by reducing the amount of OTCS and MTCS (1-10\%) in the mixture compared with the standard method. The mean diameter of the obtained particles can be significantly reduced (for example, to $0.5-1 \mu \mathrm{m}$ ) by replacing $1-5 \mathrm{~mol} \%$ of OTCS with the same amount of Span 60.

As described in the introduction, thin-film particles can be regarded as a new functional material with a broad outer surface area. These particles have potential applications as excellent supports for the preparation of new catalysts. 


\section{CONFLICT OF INTEREST}

The authors declare no conflict of interest.

\section{ACKNOWLEDGEMENTS}

We are grateful for the financial support from the Iketani Science and Technology Foundation.

1 Li, W., Sha, X., Dong, W. \& Wang, Z. Synthesis of stable hollow silica microspheres with mesoporous shell in nonionic W/O emulsion. Chem. Commun. 2434-2435 (2002).

2 Park, J.-H., Oh, C., Shin, S.-I., Moon, S.-K. \& Oh, S.-G. Preparation of hollow silica microspheres in W/O emulsions with polymers. J. Colloid Interface Sci. 266, 107-114 (2003)

3 Fujiwara, M., Shiokawa, K., Tanaka, Y. \& Nakahara, Y. Preparation and formation mechanism of silica microcapsules (hollow sphere) by water/oil/water interfacial reaction. Chem. Mater. 16, 5420-5426 (2004).

4 Song, L., Ge, X. \& Zhang, Z. Interfacial fabrication of silica hollow particles in a reverse emulsion system. Chem. Lett. 34, 1314-1315 (2005)

5 Zoldesi, C. I. \& Imhof, A. Synthesis of monodisperse colloidal spheres, capsules, and microba1loons by emulsion templating. Adv. Mater. 17, 924-928 (2005).

6 Zoldesi, C. I., van Walree, C. A. \& Imhof, A. Deformable hollow hybrid silica/siloxane colloids by emulsion templating. Langmuir 22, 4343-4352 (2006).

7 Yang, L., Wang, Y., Luo, G. \& Dai, Y. A new 'pH-induced rapid colloid aggregation' method to prepare micrometer-sized spheres of mesostructured silica in water-in-oil emulsion. Microporous Mesoporous Mater. 94, 269-276 (2006).

8 Zhang, S., Xu, L., Liu, H., Zhao, Y., Zhang, Y., Wang, Q., Yu, Z. \& Liu, Z. A dual template method for synthesizing hollow silica spheres with mesoporous shells. Mater. Lett. 63, 258-259 (2009).

9 Fan, H., Lei, Z., Pan, J. H. \& Zhao, X. S. Sol-gel synthesis, microstructure and adsorption properties of follow silica spheres. Mater. Lett. 65, 1811-1814 (2011).

10 Liu, S., Wei, M., Rao, J., Wang, H. \& Zhao, H. A controlled formation of cage-like nanoporous hollow silica microspheres. Mater. Lett. 65, 2083-2085 (2011).

$11 \mathrm{Fu}, \mathrm{X}$., He, X. \& Wang, Y. Facile preparation of silica hollow microspheres by precipitation-phase separation method. Colloids Surfaces A Physicochem. Eng. Aspects 380, 241-249 (2011).

12 Xiong, C., Coutinho, D. \& Balkus, K. J. Jr. Fabrication of hollow spheres composed of nanosized ZSM-5 crystals via laser ablation. Microporous Mesoporous Mater. 86 , 14-22 (2005).

13 Ren, N., Yang, Y.-H., Shen, J., Zhang, Y.-H., Xu, H.-L., Gao, Z. \& Tang, Y. Novel, efficient hollow zeolitically microcapsulized noble metal catalysts. J. Catal. 251, 182-188 (2007)

14 Yue, N., Xue, M. \& Qui, S. Fabrication of hollow zeolite spheres using oil/water emulsions as templates. Inorg. Chem. Commun. 14, 1233-1236 (2011).
15 Wang, L., Yang, W., Ling, F., Shen, Z., Yang, R., Sun, W., Fang, X. \& Ji, H. A facile method for the fabrication of IM-5 hollow zeolite sphere in emulsion system. Microporous Mesoporous Mater. 163, 243-248 (2012).

16 Tao, H., Ren, J., Liu, X., Wang, Y. \& Lu, G. Facile synthesis of hollow zeolite microspheres through dissolution-recrystallization procedure in the presence of organosilanes. J. Solid State Chem. 200, 179-188 (2013).

17 Chung, C.-J. \& Jean, J.-H. Synthesis of hollow titania powder by the hydrothermal method. J. Am. Ceram. Soc. 91, 3074-3077 (2008).

18 Kang, S., Yin, D., Li, X., Li, L. \& Mu, J. One-pot template-free preparation of mesoporous $\mathrm{TiO}_{2}$ hollow spheres and their photocatalytic activity. Mater. Res. Bull. 47, 3065-3069 (2012).

19 Tseng, W. J. \& Chao, P.-S. Synthesis and photocatalysis of $\mathrm{TiO}_{2}$ hollow spheres by a facile template-implantation route. Ceram. Int. 39, 3779-3787 (2013).

20 Mishima, S., Kawamura, M., Matsukawa, S. \& Nakajima, T. Preparation of a hollow microsphere composed of porous organic-inorganic hybrid wall in a W/O microemulsion system. Chem. Lett. 1092-1093 (2002).

21 Okada, T., Mishima, S. \& Yoshihara, S. One-pot synthesis of inorganic-organic hollow microsphere solid-acid catalysts in a W/O microemulsion system. Chem. Lett. 38, 32-33 (2009).

22 Okada, T., Miyamoto, K., Sakai, T. \& Mishima, S. Encapsulation of a polyoxometalate into an organosilica microcapsule for highly active solid acid catalysis. ACS Catal. 4 73-78 (2014).

23 Okada, T., Watanabe, N., Sakai, T., Haeiwa, T. \& Mishima, S. Fabrication of acidtolerant magnetic $\mathrm{Co@SiO}$ core-shell particles with dense silica shell. Chem. Lett. 40, 106-107 (2011)

24 Okada, T., Takeda, Y., Watanabe, N., Haeiwa, T., Sakai, T. \& Mishima, S. Chemically stable magnetic nanoparticles for metal adsorption and solid acid catalysis in aqueous media. J. Mater. Chem. A 2, 5751-5758 (2014).

25 Okada, T., Ozono, S., Okamoto, M., Takeda, Y., Minamisawa, H. M., Haeiwa, T., Sakai, T. \& Mishima, S. Magnetic rattle-type core-shell particles containing iron compounds with acid-tolerance by dense silica. Ind. Eng. Chem. Res. 53, 8759-8765 (2014).

26 Guizard, C. \& Princivalle, A. Preparation and characterization of catalyst thin films. Catal. Today 146, 367-377 (2009).

27 Lamic-Humblot, A.-F., Barthe, P., Guzman, G., Delannoy, L. \& Louis, C. Preparation of thin film gold based catalysts for oxidation reactions in liquid and gas phases. Thin Solid Films 527, 96-101 (2013).

28 Bian, Y., Wang, X., Zeng, Z. \& Hu, Z. Preparation of ordered mesoporous $\mathrm{TiO}_{2}$ thin film and its application in methanol catalytic combustion. Surf. Interface Anal. 45, 1317-1322 (2013).

29 Han, X., Huang, H., Zhang, H., Zhang, X., Li, H., Liu, R., Liu, Y. \& Kang, Z. Au/SiOx composite thin film as catalyst for solvent-free hydrocarbon oxidation. Mater. Res. Bull. 48, 3717-3722 (2013).

30 Smith, R. D. L., Sporinova, B., Fagan, R. D., Trudel, S. \& Berlinguette, C. P. Chem. Mater. 26, 1654-1659 (2014).

31 Ghindes-Azaria, L., Levy, E., Keinan-Adamsky, K. \& Goobes, G. Conformation and dynamics of organic tethers bound to MCM41-type surfaces from solid state NMR measurements. J. Phys. Chem. C 116, 7442-7449 (2012).

Supplementary Information accompanies the paper on Polymer Journal website (http://www.nature.com/pj) 